\title{
Impacts of innovation, productivity and specialization on tourism competitiveness - a spatial econometric analysis on European regions
}

\section{João Romão \& Peter Nijkamp}

To cite this article: João Romão \& Peter Nijkamp (2019) Impacts of innovation, productivity and specialization on tourism competitiveness - a spatial econometric analysis on European regions, Current Issues in Tourism, 22:10, 1150-1169, DOI: 10.1080/13683500.2017.1366434

To link to this article: https://doi.org/10.1080/13683500.2017.1366434

曲 Published online: 22 Aug 2017.

Submit your article to this journal $\pi$

ЏIII Article views: 777

Q View related articles $\asymp$

View Crossmark data \lceil

Citing articles: 25 View citing articles $\sqsubset$ 


\title{
Impacts of innovation, productivity and specialization on tourism competitiveness - a spatial econometric analysis on European regions
}

\author{
João Romão (iD ${ }^{a *}$ and Peter Nijkamp ${ }^{\mathrm{b}}$ \\ ${ }^{a}$ Faculty of Economics, Centre for Advanced Studies in Management and Economics, University \\ of Algarve, Gambelas Campus, 8005-139, Faro, Portugal; ${ }^{b}$ Tinbergen Institute, Gustav \\ Mahlerplein 117, 1082 MS Amsterdam, Netherlands
}

(Received 30 May 2016; accepted 5 August 2017)

\begin{abstract}
Tourism is clearly a place-based activity, while in many advanced economies it is increasingly becoming a knowledge-based activity, with a high potential for the development of practice- and place-based innovation strategies. This study analyses whether and how regional systems of innovation influence the competiveness of tourism destinations in Europe. Impacts of both traditional production factors (physical and human capital), productivity, specialization and other contextual variables - related to the territorial capital of each region - on regional tourism performance of 237 European regions (NUTS 2) are analysed over a period of 8 years, using advanced techniques for spatial econometric analysis. The results reveal lower levels of productivity in those regions where tourism services are more labour intensive, while regions where education, innovation and productivity demonstrate higher levels are those where gross value added in tourism is less important for the regional economy. Policy implications are discussed, taking into consideration the principles for smart specialisation strategies in European regions and the possibility for cross-border regional cooperation. This work also confirms the research potential of spatial econometric analysis - and in particular spatial autocorrelation techniques for tourism studies.
\end{abstract}

Keywords: productivity; innovation; specialization; territorial capital; spatial econometrics; panel data

\section{Introduction}

Tourism is clearly a place-based activity, while in many advanced economies it is increasingly becoming a knowledge-based activity (Racherla, Hu, \& Hyun, 2008). Co-terminality (direct interaction between producer and consumer), as well as spatiality and temporality (consumption and production of tourism services occur in the same place at the same time) distinguish tourism from other economic activities. These factors enhance its potential for the development of practice- and place-based innovation strategies based on information and knowledge (the info-structure for tourism development, as defined by Buhalis \& Law, 2008), arising from the interaction between producers and consumers, while contributing to the emergence of the concept of "smart tourism" (Boes, Buhalis, \& Inversini, 2016). Tourism destinations are multi-product areas for multi-segment markets where local small product and service providers interact with large international companies and with costumers from all over the world. At the same time, the spatial agglomeration of

\footnotetext{
*Corresponding author. Email jfromao@ualg.pt
} 
tourism activities potentially generates positive externalities for the regional economy. The regional analysis developed in this work offers two types of new contributions for the analysis of tourism dynamics in Europe. First, regional innovation dynamics and its implications for tourism performance will be analysed and measured through an econometric model, whose results will be discussed taking into consideration the recently adopted concept of smart specialization (Foray et al., 2012). As synthetized by Boschma (2016), endogenous resources and inter-sectorial spillovers, aiming at a process of niche specialization supported by research and development activities, are core elements of the smart specialization process. On the other hand, Piirainen, Tanner, and Alkærsig (2017) suggest that smart specialization processes can follow different paths even within the same industry, exemplifying the application of information and communication technologies (ICT) to tourism services as one of the possible processes of structural economic change (modernization).

Second, a spatial dimension is introduced in our econometric model, aiming at identifying different spatial patterns among European regions regarding the relation between innovation dynamics and tourism performance. This innovative approach aims at offering relevant insights, taking into consideration that research-intensive industries in Europe tend to be regionally concentrated, with increasing regional inequalities in terms of economic development (Hansen \& Winther, 2011) and high dependence on the geographical and historical conditions influencing regional development trajectories (Martin, 2014). Additionally, as Milio (2014) observed, regions highly specialized in tourism and construction have revealed a lack of resilience after the international crisis started in 2007, with major difficulties to recover their trajectories of employment and economic growth. In a similar vein, Romão and Neuts (2017) observed that European regions with high specialization in tourism (measured by the share of the employment in this sector in the regional labour force) tend to exhibit lower levels of gross value added in this sector, along with lower levels of education of the population.

Against the background of existing relevant and comparable data, which are appropriate for an international comparison in the tourist sector, this study examines whether and how the development of regional systems of innovation (Cooke, 2001; Asheim, Smith, \& Oughton, 2011) influences the regional tourism competitiveness. Despite the recognized importance of technological development for recent tourism growth and transformation, this question - and, in particular, the related spatial patterns observed at the European level - has not been addressed and systematically evaluated.

The research includes a general inventory and overview of the data for the different variables included in the model based on a geographical representation presented in the second section. Next, an exploratory spatial analysis based on local Moran-I indicators of spatial association between tourism performance and the explanatory variables taken into consideration is offered. This statistical approach is complemented with maps in the third section, in order to capture and visualize the spatial effects arising from the interaction among tourism areas. Finally, an advanced econometric approach based on a spatial panel data model is presented and developed in the fourth section, aiming to provide a quantified explanation of the impacts of each explanatory variable - and the related spatial effects - on regional tourism performance. A discussion of the main results of this analysis and its policy and managerial implications will be offered in the concluding section.

\section{Literature review and conceptual framework}

Recent developments and innovations in ICT have radically transformed the tourism business, increasing its potential for interactivity and cooperation. These new processes 
of interaction contribute to a better understanding of the needs and motivations of tourists, to reach specific targets with oriented and personalized information (Neuts, Romão, Nijkamp, \& van Leeuwen, 2013) and to increase the buyers' bargaining power (increased convenience, transparency, flexibility and interactivity), making information a key element to match supply and demand of tourism services (Tussyadiah \& Fesenmaier, 2009).

As most of the tourism services are provided by small- and medium-sized companies (SMEs) - often with limited structured formal learning processes - the information obtained through their interaction with tourists tends to be tacit (requiring codification and adaptation to lead to innovative processes) and localized (the destination becomes a repository of unique and inimitable knowledge which represents a high potential for innovation). This enhances the importance of regional innovation networks for innovation (Hjalager, 2010), as was also suggested by the European Commission (2006) when the "tourism learning area" concept was proposed. Nevertheless, as Tödtling and Kaufmann (2001) point out, SMEs are generally less engaged in networks for innovation, not taking advantage of this potential.

New practices oriented towards personalized needs and based on new internet services ("Web 2.0") enhance the potential for the development of processes of co-creation of services (Liburd \& Christensen, 2013) or may even to become "tools of mass collaboration" (Sigala, 2009), with significant impacts on innovation processes (Sigala, 2012), collaborative governance models (Sigala \& Marinidis, 2012) or education and training (Liburd \& Christensen, 2013). A systematization of these developments and impacts is proposed by Boes et al. (2016), when defining a "smart tourism destination". The broad interpretation of the tourism sector adopted in our work follows this comprehensive approach, including ICT and social services.

Assuming the difficulties in measuring the material and immaterial aspects defining the regional innovation systems and, in particular, their relation with tourism (as pointed out by Rodríguez, Williams, \& Hall, 2014), our work assumes the regional investment in Research and Development (R\&D) activities and the qualifications of the labour force as two variables that can offer a comparative overview at international level of the innovative environment in each region. This approach can framed within the macro-level of analysis, as defined by Medina-Muñoz, Medina-Muñoz, and Zuñiga-Collazos (2013b), by focusing on the impacts of innovative networks and regional innovation systems on the tourism sector. Additionally, and considering the importance of cross-border regional innovation systems for tourism dynamics stressed by Weidenfeld (2013), our work includes a spatial analysis aiming at the identification of spatial patterns and agglomeration processes potentially reinforcing this innovative dynamics.

In the last years, several studies have addressed the importance of the qualifications of the labour force for innovation dynamics and performance of the tourism sector in different contexts. In particular, Yang and Cai (2015) found that labour quality and specialization have strong positive impacts in the performance of high ranking hotels, while ÚbedaGarcía, Cortés, Marco-Lajara, and Zaragoza-Sáez (2014) observed that human capital development has higher positive impacts in hotels following a strategy of differentiation. Special importance to labour productivity is given by Cvelbar, Dwyer, Koman, and Mihalič (2015), assuming the contribution to GDP per worker in the tourism sector (one of the explanatory variables in our model) as a measure of tourism competitiveness.

Tourism competitiveness has been broadly analysed in the last two decades, with different formulations and indicators (e.g. Dwyer \& Chulwon, 2003; Enright \& Newton, 2004; Hassan, 2000; Kozak, 1999; Navickas \& Malakauskaite, 2009; Ritchie \& Crouch, 2003; Tsai, Song, \& Wong, 2009). A synthesis of these contributions is proposed by Song, 
Dwyer, and Cao (2012), while the importance of this question is also expressed through the definition of indicators or policy guidelines at international level (e.g. European Commission, 2007; World Economic Forum, 2015). Camisón and Forés (2015) highlight the importance of territorial characteristics for the agglomeration of innovative tourism activities, proposing the concept of "tourism districts" in their analysis of competitiveness. In that sense, the spatial dimension introduced in our analysis aims at capturing - at least partially - this spatial dimension and possible territorial inequalities.

Mazanek, Wober, and Zins (2007) and Medina-Muñoz, Medina-Muñoz, and ChimMiki (2013a) point out that, even though most of these analysis contribute to the explanation of tourism competitiveness, they do not necessarily adopt a definitional perspective, once the determinants of competitiveness are not linked to output indicators. According to the model for measuring and explaining destination competitiveness proposed by MedinaMuñoz, Medina-Muñoz, and Chim-Miki (2013a), an overall and suitable way of analysing tourism competitiveness must adopt indicators from the definitional approach (e.g. indicators related to the ability to attract visitors) as well as the explanation approach (e.g. production and contextual factors). Therefore, these authors suggest a structural model approach, where variables related to market share and demand growth are causally related to the factors determining competitiveness, aiming at an explanatory approach, with more relevant policy and managerial implications. Our analysis shares this type of concern, by establishing a causal relationship between some major determinants and a quantitative measure of tourism competitiveness.

When defining a competitive tourism destination, Ritchie and Crouch (2003) refer to

the ability to increase tourism expenditure, to increasingly attract visitors, while providing them with satisfying, memorable experiences, and to do so in a profitable way, while enhancing the well-being of destination residents and preserving the natural capital of the destination for future generations.

Thus, the ideas of growth, economic impacts and benefits for the host community and consumer satisfaction are crucial for tourism competitiveness. In that sense, although our analysis is not primarily focused on the determinants of tourism destination competitiveness, the measurement of tourism performance we propose (based on the gross value added by the tourism sector) can be framed within this strand of competitiveness studies.

Despite the close link between tourism and territory, the utilization of spatial analysis methods in tourism studies is rather recent and still relatively rare, with a relatively small number of studies being published in the last few years. Focusing on a territorial scale of analysis similar to the level proposed in our study, Zhang, $\mathrm{Xu}$, and Zhuang (2011), Yang and Wong (2012), Patuelli, Mussoni, and Candela (2013), Kang, Kim, and Nicholls (2014), Yang and Fik (2014), Ma, Hong, and Zhang (2014), Paci and Marrocu (2014) or Romão, Rodrigues, and Guerreiro (2017) have found positive impacts of tourism dynamics in one region on the performance of neighbouring regions. Nevertheless, it was also observed that the magnitude of these impacts is diverse in different places and also over time. Additionally, heterogeneous features of tourism activities (e.g. the impacts of national or foreign tourists) have revealed different spatial impacts.

A synthesis of the potential spillover effects related to tourism arising from the spatial interaction between regions is offered by Yang and Wong (2012), suggesting the existence of "productivity spillovers" (related to labour movement, demonstration effects or 
competition effects) or "market access spillovers" (related to joint promotion plans, reactions to negative events, or exploration of opportunities related to multi-destination travel plans adopted by a large number of tourists.)

In our original framework, the impacts of both traditional production factors (physical and human capital) and contextual variables related to the territorial capital of each region (such as level of specialization in tourism, intensity of innovation, labour qualification or productivity) on regional tourism performance (expressed by the evolution of gross value added generated by tourism in each region) will be analysed. The study covers a period of 8 years (including a period of unprecedented expansion of tourism activities, negative economic effects caused by the international crisis and the gradual effects of the processes of recovery) and uses modern and advanced techniques of spatial analysis in order to identify possible heterogeneity or agglomeration effects among European regions. This research plan is mapped out in Figure 1.

\section{Territory and tourism performance: data and variables}

This study covers a large number (237) of NUTS-2 regions in the European Union. All regions (except the islands, due to the estimation problems arising when working with spatial panel data models) from Austria, Belgium, Bulgaria, Czech Republic, Denmark, Estonia, Finland, France, Germany, Greece, Hungary, Italy, Latvia, Lithuania, Luxemburg, Netherlands, Poland, Portugal, Romania, Slovakia, Slovenia, Spain and the United Kingdom have been included. Thus, this sample includes a large number of regions, with different levels of tourism dynamics, specialization and very diverse characteristics for their territorial capital.

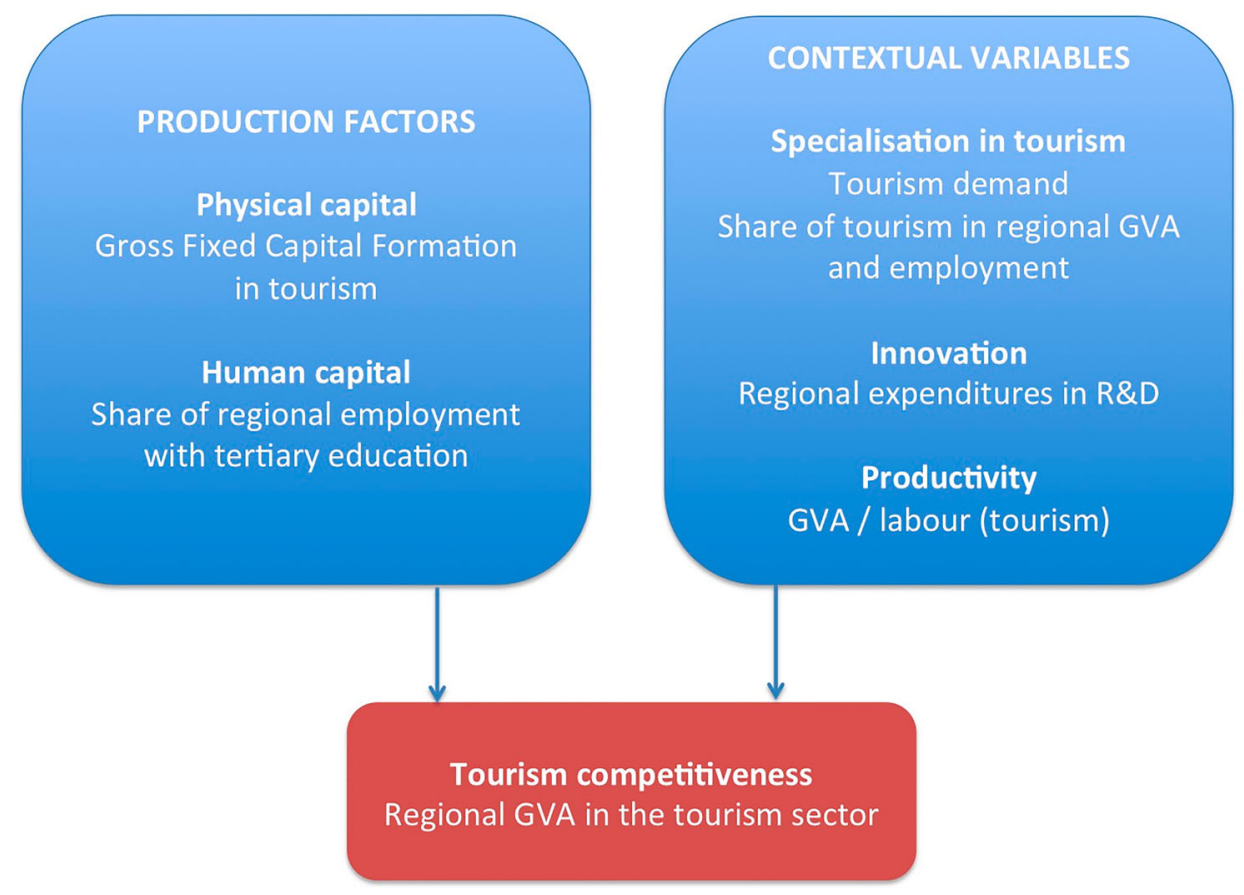

Figure 1. Architecture of the conceptual model. 
NUTS-2 regions are relevant for the purposes of this analysis, as they generally have a specific institutional framework for regional and tourism policies and exhibit also some territorial coherence, although, in a strict sense, they cannot exactly be considered a tourism destination (normally, there is more than one tourism destination in each NUTS 2 region). Moreover, this territorial level of analysis is of particular relevance in order to observe the structural characteristics and evolution of regional economic systems, their innovation dynamics, inter-sectorial relations or human resource endowment, which tend to be difficult to access at the destination level. Thus, the policy and managerial implications of our results can be addressed at an appropriate territorial and institutional level.

The dependent variable considered in the spatial panel model to be estimated is a proxy for tourism competitiveness, measured on the basis of the regional gross value added (at current prices) by tourism activities, which is appropriate to assess several important dimensions of tourism competitiveness, including the economic impacts for the host communities. When observing a period of 8 years, this indicator also reveals the process of tourism growth in a destination, which generally is, at least implicitly, connected to the satisfaction of visitors. Thus, although our purpose is not to offer a detailed analysis of the determinants of tourism competitiveness, the utilization of this indicator can be clearly framed within competitiveness studies.

A broad definition of tourism services has been addressed in this paper (including wholesale and retail trade; transport; accommodation and food service activities; ICT services), according to the available data provided by Eurostat (when missing data occurred, they were calculated according to the existing information, while taking into consideration the trends immediately before or after the missing information). This broad definition of tourism services incorporates the importance of ICT for contemporary tourism. Even though the importance of these services may emerge from factors not related to tourism, it turned out to be possible to obtain interesting and relevant results for the purposes of this analysis. The positive correlation identified between this indicator and tourism demand (expressed by the number of overnight stays in each region) clearly reveals its adequacy for the purposes of this analysis.

The values for the most recent year under analysis regarding gross value added in tourism for each region are presented in the left-hand side of Figure 2 (the maps were created based on quintiles, implying that a similar number of region is included in each class and the same methodology has been adopted for the subsequent maps). Clearly, it
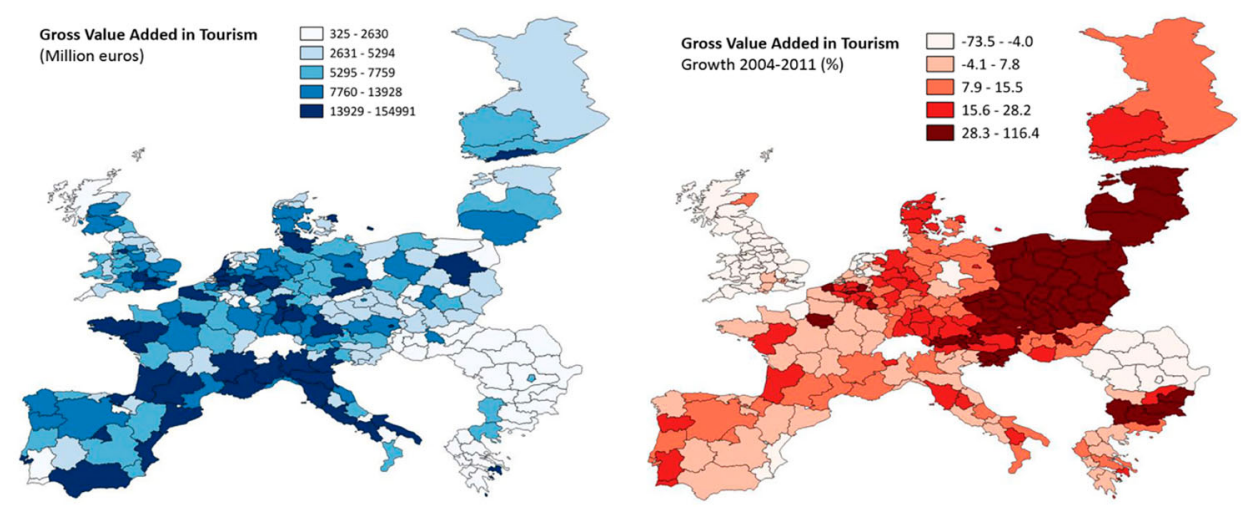

Figure 2. Gross value added in tourism (million euro, 2011; growth rate 2004-2011). 
is possible to observe the tourist importance of South and West European regions on this map. Nevertheless, when observing the map in the right-hand side of Figure 2 - representing the growth of regional gross value added in tourism during the period under analysis (2004-2011) - a shift to the Eastern side of Europe can be noticed. This reflects the increasing importance of tourism in these areas, but this is also related to inflationary processes linked to the integration of countries like Poland, Latvia, Lithuania or Estonia into the European Union.

The determinants of the regional tourism performance considered relate to the importance of tourism in the regional economy (share of tourism in regional employment and gross value added, measuring the level of tourism specialization; and tourism demand measured by the nights spent at regional tourism accommodation establishments), production factors (human capital, measured by the level of education of the work force; and physical capital, measured by the gross fixed capital formation in the tourism sector) and immaterial regional resources (productivity and regional investment in research and development). These indicators reflect the territorial capital of each region, broadly defined as the regional ability to transform resources into competitive products and services (Capello, Caragliu, \& Nijkamp, 2011; Basile, Capello, \& Caragliu, 2012). These data were also obtained from Eurostat and, while following the same methodology as for the dependent variable, missing information was calculated considering the trends immediately before or after the missing data.

The share of tourism (again based on a broad definition that includes wholesale and retail trade; transport; accommodation and food service activities; ICT services) in regional employment and gross value added is represented in Figure 3, showing different spatial patterns for tourism specialization at European level. The map representing employment (left side) reveals the importance of tourism in Southern Europe (mainly the regions from Portugal, Spain, Italy and Greece) but also some Northern Eastern countries (Latvia and Lithuania). On the other hand, the map representing the share of value added (right side) shows that tourism-related activities assume a larger importance in regions from Poland or United Kingdom, while this importance decreases in some of the Southern regions where employment for this sector was traditionally shown to be important. This also reflects regional differences in productivity (gross value added per worker), represented in Figure 4. In this case, the map for 2011 (left side) suggests that regions in Central Europe are the most productive regarding tourism services, while the map reflecting the evolution between 2004

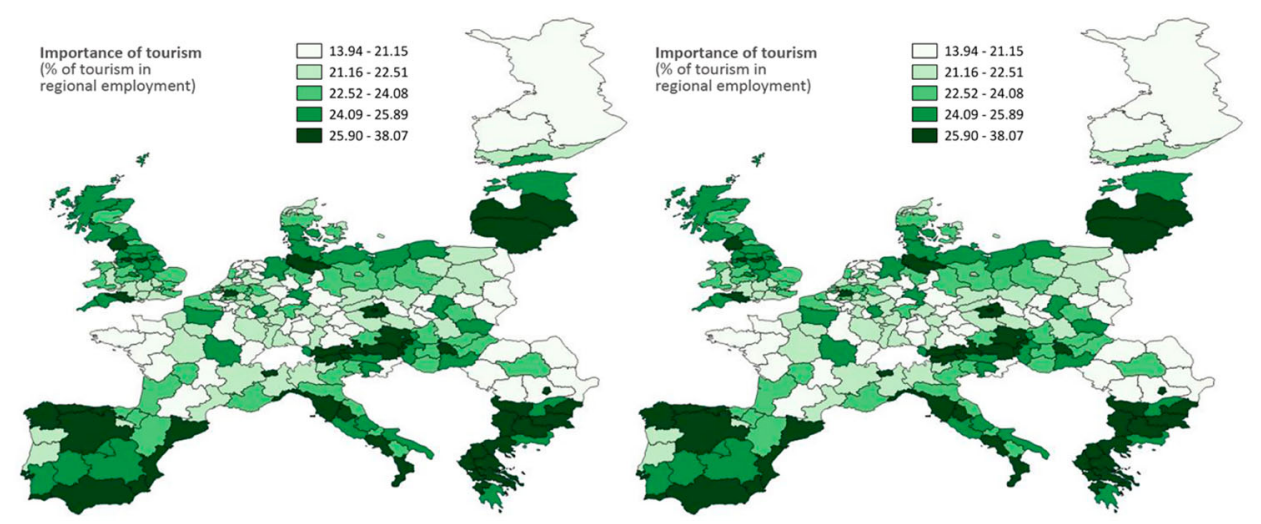

Figure 3. Share of tourism in regional employment and gross value added (percentage, 2011). 

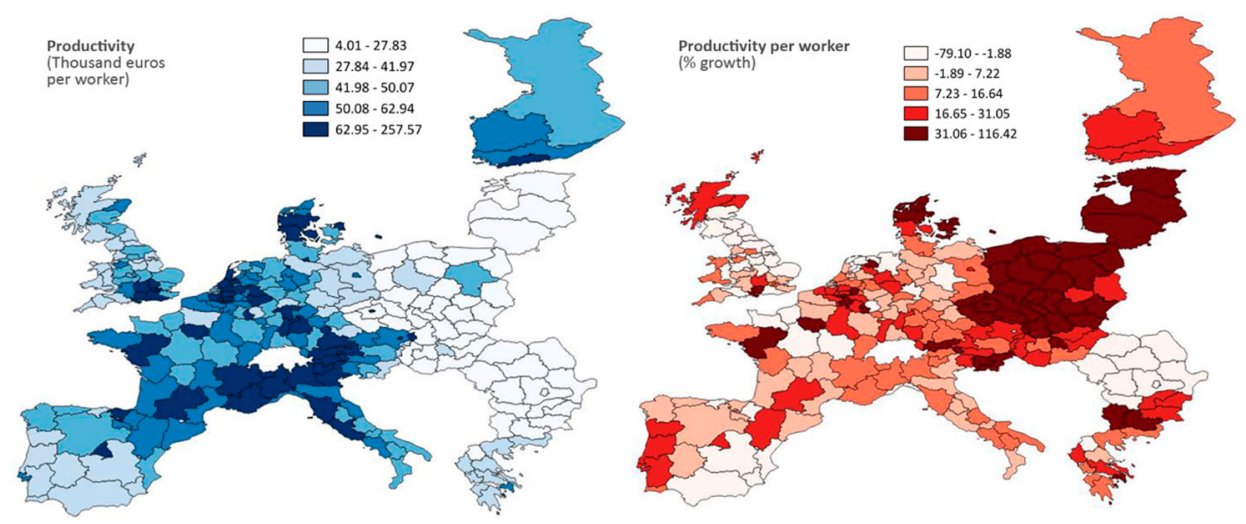

Figure 4. Productivity in tourism (thousand euro per worker, 2011; growth rate 2004-2011).

and 2011 (right side) reveals the high growth of productivity registered in Eastern European during the last years, as was also observed for gross value added.

The immaterial factors that may significantly contribute to regional tourism performance considered in this research are represented in Figure 5, considering the data for 2011. The map on the left side shows the percentage of the regional labour force with tertiary education, measuring the levels of qualification of the workers in each region. With the exception of some regions in the North of Spain, it is possible to observe that, generally, the highest levels of qualification are registered in North-European countries. A similar pattern can be found for the regional expenditures in research and development (as a percentage of regional gross domestic product), represented in the right side. In this case, the exceptions for the North of Spain are not observed.

Finally, when the investment in physical infrastructures for tourism (gross fixed capital formation, in million euros, in the tourism sector) is taken into consideration, there is a clear dominance of the South-European regions, where the major mass sun and seadestinations are located (Figure 6). This suggests that the high specialization in tourism activities observed in these regions tend to be reinforced, considering the dominance of this sector regarding the regional investment.

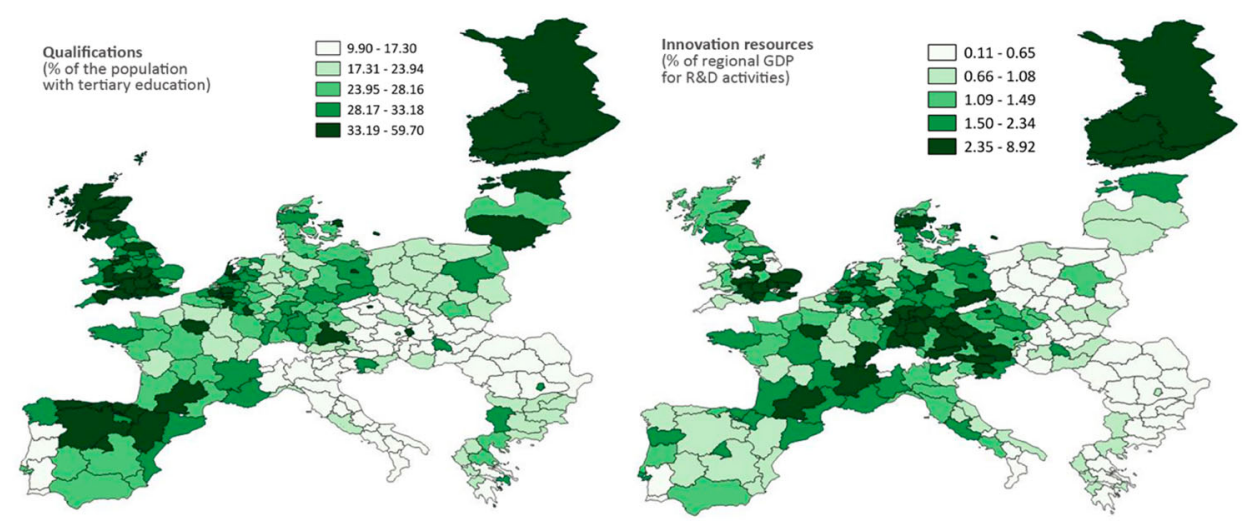

Figure 5. Qualifications (percentage of the labour force with tertiary education, 2011) and innovation efforts (percentage of the regional GDP, 2011). 
Investiment in tourism

(Gross Fixed Capital Formation, million euros)
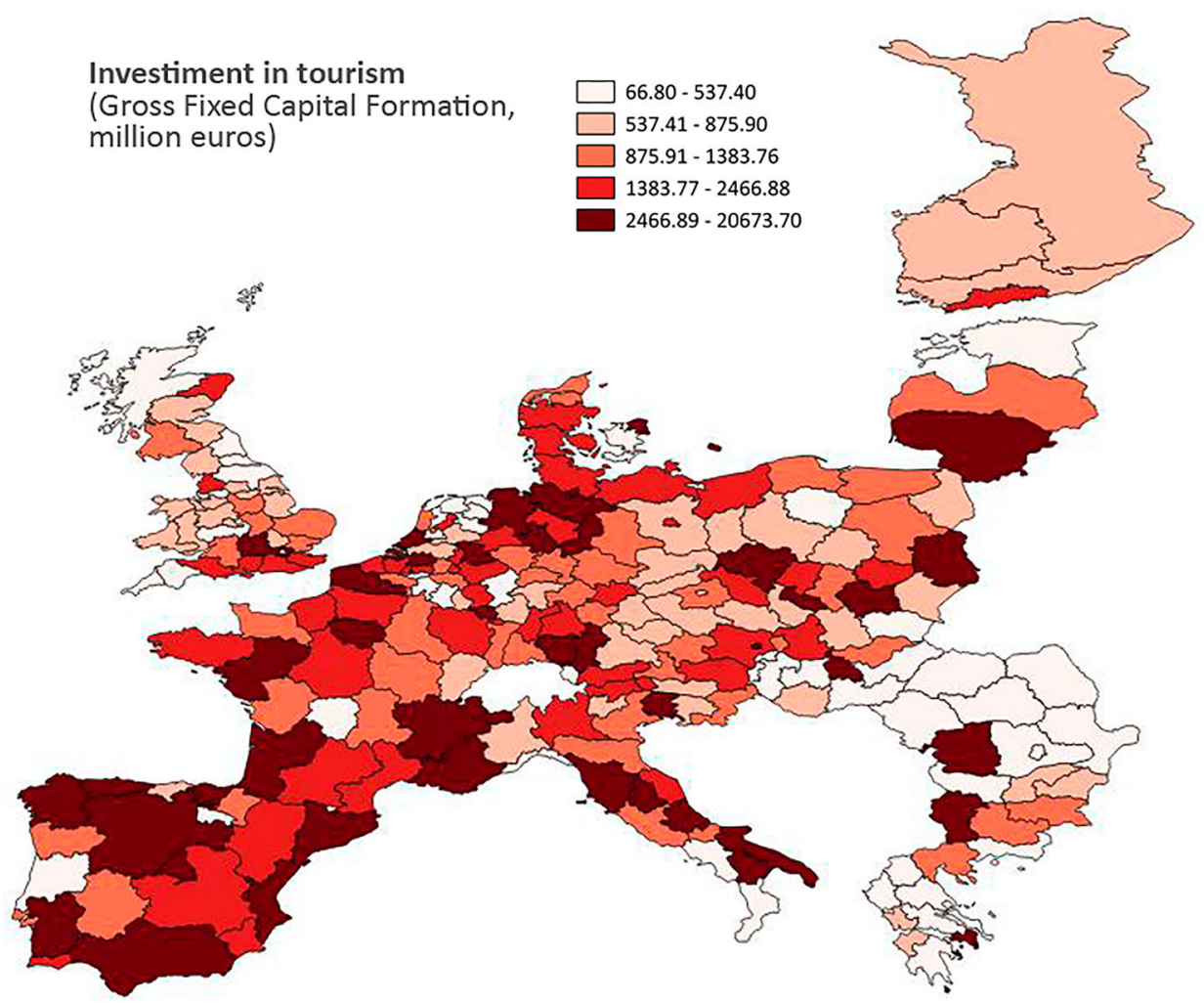

Figure 6. Gross fixed capital formation in tourism (million euros, 2011).

\section{The territorial dimension of tourism: exploratory spatial data analysis}

Tourism regions are normally not islands in isolation and tourism flows are often crossing regional borders. In this sense, spatial analysis and spatial econometrics can offer useful tools to identify and explain different patterns of regional tourism dynamics and their determinants. As stressed by Anselin (2010), these techniques became widely used in applied economic studies, as a result of their useful insights to understand spatial phenomena and also benefiting from the existence of geo-referenced data and adequate software tools.

The existence of such spatial effects can be tested using Global and Local Indicators of Spatial Association (Anselin, 2005) by introducing spatially lagged variables (the value for each region is defined according to the average value for its neighbours). Some authors have recently applied similar techniques in tourism studies, in different locations and territorial scales, with different purposes (e.g. Kang et al., 2014; Zhang et al., 2011; or Majewska, 2015), leading to the identification of different patterns of spatial heterogeneity for the distribution of tourism activities, which tend to concentrate around specific clusters of regions.

For the purposes of our analysis, a geographic neighbourhood here is defined according to the second-level rook-contiguity criteria (two regions are neighbours if they share a common border, including a first contiguity level - direct neighbours - and a second contiguity level - "neighbours of neighbours"), assuming that spillovers arising from tourism activities can spread for these two levels of proximity. This information is used to build a spatial weight matrix that defines the impacts of each region on its neighbours. Two additional conditions are defined: the spatial weight matrix is row normalized (assuming 
Table 1. Moran-I test for spatial autocorrelation.

\begin{tabular}{ccccccccc}
\hline $\begin{array}{c}\text { LOGGVAT } \\
11\end{array}$ & $\begin{array}{c}\text { LOGNIG } \\
11\end{array}$ & GVATS11 & EMPTS11 & $\begin{array}{c}\text { LOGINV } \\
11\end{array}$ & $\begin{array}{c}\text { EDUC } \\
11\end{array}$ & ID 11 & $\begin{array}{c}\text { PROD } \\
11\end{array}$ \\
\hline$z$-Score & 3.280 & 11.792 & 9.825 & 8.396 & 4.274 & 19.040 & 8.520 & 12.511 \\
\hline
\end{tabular}

that all relevant regions have the same potential to generate spillovers) and the impact on the direct first-level neighbour is twice as large as the impact on the second level. Although this process is based on one ad hoc assumption (though rather plausible), it will lead to some statistically relevant results. Similar methodologies for the estimation of this impact matrix have been adopted in tourism studies by Zhang et al. (2011), Mata and Llano-Verduras (2012), Marrocu and Paci (2013) or Kang et al. (2014).

A measure for the global spatial correlation between neighbours can be obtained with the Moran-I test (a global indicator of spatial autocorrelation, computed with Geoda 1.6.0 based on the methodologies presented by Anselin, 2005) (Table 1). The existence of spatial effects is identified when the $z$-score obtained is above the threshold of 1.96 , for a $5 \%$ significance level. The results obtained for each variable in the last year of observation (2011) are shown in Table 2, clearly suggesting the existence of spatial effects

A bivariate analysis relating the dependent variable of the model (non-lagged) to each of the dependent variables (lagged) has also been conducted, in order to identify clusters of regions with similar patterns. These clusters occur when the value obtained for the nonlagged variable is more similar (positive autocorrelation) or dissimilar (negative autocorrelation) to the value of the lagged variable (the weighted average of the neighbouring values) than it would be in case of spatial randomness. This analysis was based on Local Moran-I indicators of spatial autocorrelation and also computed with Geoda 1.6.0 (Anselin, 2005).

The following figures represent the results obtained in this analysis at a $95 \%$ significance level. Regions positively correlated are represented with dark colours (with white lines for high values for both variables and plain colour for low values for both variables), while light colours represent a negative correlation (with black lines for high values of the nonlagged variable and low values for the lagged variable, and plain colour for the reverse).

The first map in Figure 7 (left) identifies clusters of high values of regional performance in tourism (measured by gross value added in this activity) and of high tourism demands in the Southern European regions from Spain, France and Italy (dark colour with line). Nevertheless, it is also noticeable that there exists a large number of Southern regions (in the same countries) where low value added in tourism has a clear spatial autocorrelation with high tourism demand

Table 2. Estimates for a spatial lag model with fixed (time) effects.

\begin{tabular}{lrrrcc}
\hline Parameters & Estimate & Std. error & $t$-Value & $\operatorname{Pr}(>|t|)$ & Significance \\
\hline Intercept & 0.321 & 0.144 & 2.222 & 0.027 & 0.05 \\
log NIT & 0.194 & 0.012 & 15.565 & $<2.2 \mathrm{e}^{-16}$ & 0.001 \\
logINV & 0.631 & 0.012 & 52.642 & $<2.2 \mathrm{e}^{-16}$ & 0.001 \\
EMPTS & -0.006 & 0.003 & 1.979 & 0.048 & 0.05 \\
GVATS & 1.283 & 0.128 & 10.040 & $<2.2 \mathrm{e}^{-16}$ & 0.001 \\
EDUC & 0.005 & 0.002 & 3.147 & 0.002 & 0.01 \\
ID & 0.077 & 0.009 & 8.843 & $<2.2 \mathrm{e}^{-16}$ & 0.001 \\
Prod & 0.003 & 0.001 & 6.561 & $<2.2 \mathrm{e}^{-16}$ & 0.001 \\
Spatial autoregressive coefficient $(\rho)$ & 0.534 & 0.031 & 17.160 & $<2.2 \mathrm{e}^{-16}$ & 0.001 \\
Spatial autocorrelation coefficient $(\lambda)$ & 0.062 & 0.025 & 2.490 & 0.013 & 0.05 \\
\hline
\end{tabular}




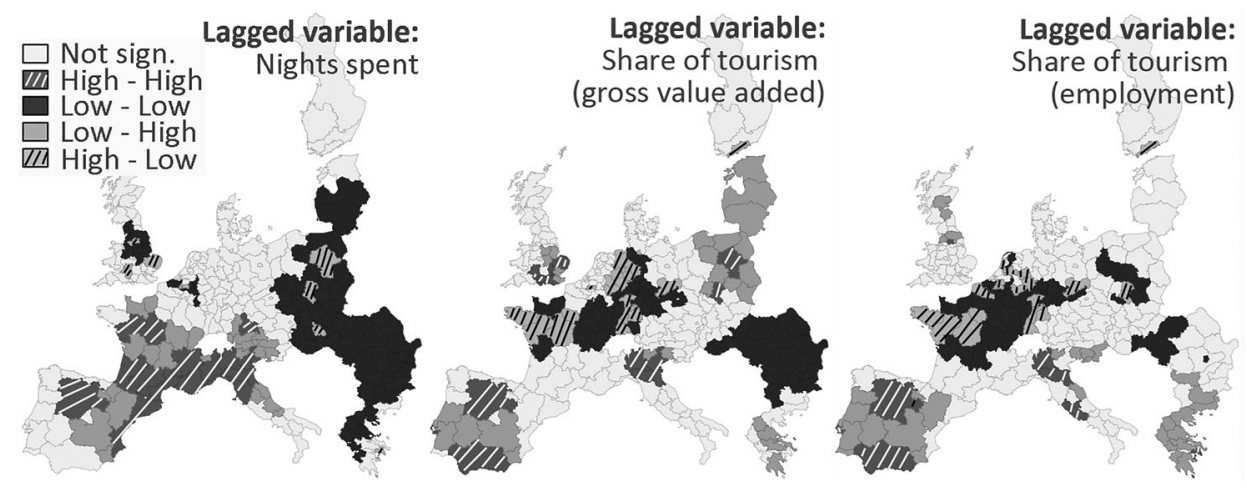

Figure 7. Local Indicators of Spatial Autocorrelation - bivariate analysis (1).

(light plain colour), suggesting the existence of a tourism supply based on low value-added products and services, with relatively low productivity. On the other hand, clusters of low values for both variables can generally be found in Eastern European regions (dark plain colour), despite the existence of a few exceptions within this area (and also in the United Kingdom), where a reverse pattern occurs (low tourism demand is linked to high value added in tourism).

The other two maps in Figure 7 compare regional tourism performance with the degree of specialization in this activity, measured by the share of tourism in regional gross value added (map in the centre) and in regional employment (map in the right side). For the first case, it is possible to observe a high dispersion of clusters of regions with a positive spatial autocorrelation. Some regions from Portugal, Spain and Italy, but also in the United Kingdom or North Eastern Europe, show high values for both variables, linking high performance to high specialization in tourism. On the other hand, clusters of regions with low performance and low specialization are located in Central or Eastern European regions.

Central Europe is the area where clusters of regions with high performance and low specialization can be identified (mostly in the North of France and Germany), suggesting high productivity in tourism services, although this sector is not predominant in the regional economy. The other type of negative spatial autocorrelation occurs in important parts of the territories from Portugal, Spain, Greece or North Eastern regions, revealing a high importance of tourism for the regional economy, but low achievements in terms of value added (low productivity). A similar pattern is observed if specialization is measured according to the share of tourism in regional employment, although, in this case, Greek regions assume more importance (replacing Northern Eastern European regions). This suggests the existence of even lower levels of productivity in these regions, once the gross value added by tourism is not sufficient to assume an important share of the overall gross value added, although the employment in this sector assumes a relatively high importance within the overall regional employment.

Figure 8 represents the spatial autocorrelation patterns regarding the relation between regional tourism performance, productivity (map at the left-hand side), education of the work force (map in the centre) and regional expenses in research and development (map at the right-hand side). It is possible to observe, for all cases, a large number of clusters with low levels of performance in tourism and low levels for productivity, education and R\&D (mostly in Eastern European regions). On the contrary, very few clusters of regions exist where high levels of tourism performance are related to high scores achieved in any of those three factors. If productivity, education and $R \& D$ have a high positive 

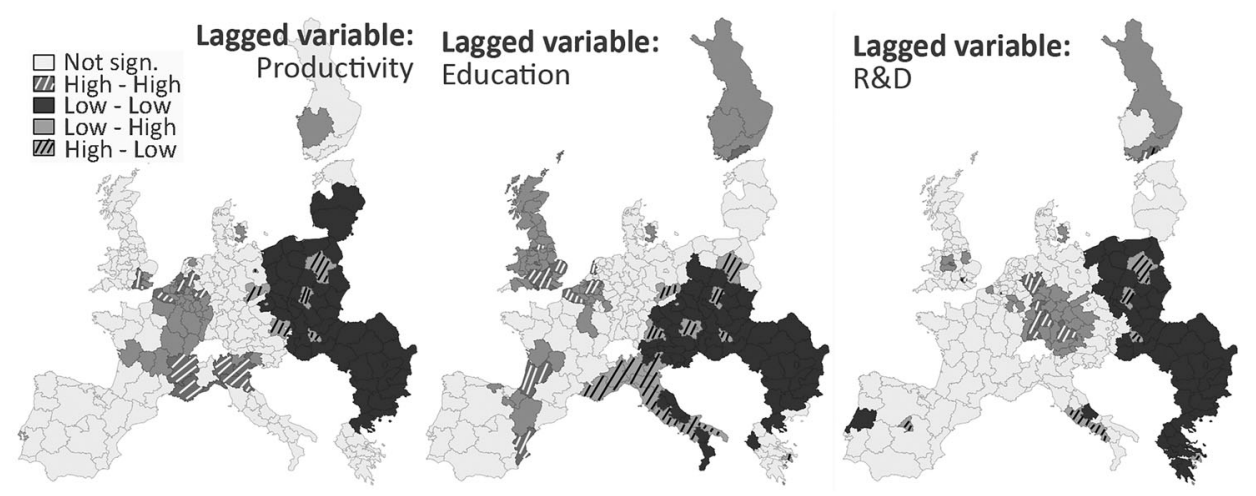

Figure 8. Local Indicators of Spatial Autocorrelation - bivariate analysis (2).

impact on regional performance, it is possible to conclude that regions scoring higher in these indicators are less dependent on tourism activities, with other sectors assuming more importance within their regional economic structure.

Finally, we also observe in Figure 8 the existence of a large number of clusters of regions with low values for gross value added in tourism, despite the high scores registered for productivity, education and R\&D in the area where they are located. Again, this confirms the abundance of regions where these factors are more developed and tourism is less important within the regional economy. On the contrary, there is a low number of regions registering the reverse situation (high value added in tourism with low scores for productivity, innovation and education).

\section{Determinants of tourism demand: a spatial panel model}

After the exploratory statistical findings in Section 3, it is now pertinent to look for an explanatory model approach. A spatial panel data model is an adequate tool for this purpose, as it allows the estimation of a model including a time series and cross-sectional data set, with information related to a large number of units (NUTS-2 regions) over 8 years, taking into consideration the potential spatial effects (Elhorst, 2003, 2014; Florax \& Vlist, 2003).

For computational purposes, natural logarithms were applied to the data related to the dependent variable, measuring tourism competitiveness (gross value added in the tourism sector - "logGVAT"), and to the independent variables related to tourism demand (nights spent in tourism accommodation establishments - "logNIT") and investments in tourism (gross fixed capital formation in the tourism sector - "logINV"); the importance of tourism in the regional gross value added (GVATS) and employment (EMPTS) is expressed in percentage, which is also the case for the immaterial factors of performance (work force with tertiary education - "EDUC" - and investment in research and development as a share of the regional GDP - "ID"). Productivity ("PROD") is expressed here in millions of euros per worker. At this initial stage, spatial effects are not considered and the equation expressing this relation is therefore defined as:

$$
\begin{aligned}
\log \mathrm{GVAT}_{\mathrm{it}}= & \beta_{0}+\beta_{1} \log \mathrm{NIT}_{\mathrm{it}}+\beta_{2} \log \mathrm{INV}_{\mathrm{it}}+\beta_{3} \mathrm{EMPTS}_{\mathrm{it}}+\beta_{4} \mathrm{GVATS}_{\mathrm{it}} \\
& +\beta_{5} \mathrm{EDUC}_{\mathrm{it}}+\beta_{6} \mathrm{ID}_{\mathrm{it}}+\beta_{7} \mathrm{PROD}_{\mathrm{it}}+{ }_{\mathrm{it}} u_{\mathrm{it}},
\end{aligned}
$$

where $i$ is an index for the regions, $t$ is an index for the time period, and $u$ is the error term. 
All the scores obtained for a Variance Inflation Test (VIF), computed with the package car in $R$, were clearly below the threshold of 5 (O'Brien, 2007), revealing the absence of problems caused by multicollinearity $(\log \mathrm{NIT}=1.839 ; \log \mathrm{INV}=1.921 ; \quad \mathrm{EMPTS}=$ 1.134; GVATS $=1.133 ;$ EDUC $=1.638 ;$ ID $=1,486 ;$ PROD $=1.818)$.

The computation of a spatial panel model regression implies the inclusion of a spatially lagged endogenous variable, measuring the impact of the growth of tourism performance in one region on its neighbours. This variable is considered as one more explanatory variable and it potentially captures eventual endogenous interaction effects (spatial lags). On the other hand, a spatial multiplier is also included in order to capture unmodelled spatial effects potentially existing in the distribution of the error term (spatial error). The existence of these spatial effects (spatial lag and spatial error) will be tested before the computation of the model. A space-time panel data model with spatial effects among the dependent variables and the error term can be specified, in a general form, as:

$$
\begin{gathered}
Y_{\mathrm{it}}=\rho W Y_{\mathrm{it}}+X_{\mathrm{it}} \beta+u_{\mathrm{it}}, \\
u_{\mathrm{it}}=\lambda W u_{\mathrm{it}}+\varepsilon_{\mathrm{it}}
\end{gathered}
$$

In this case:

- $Y$ represents the dependent variable (gross value added in tourism, as a proxy for tourism competitiveness);

- $X$ is a vector that represents the independent variables:

- Number of nights in tourism establishments, as a proxy for tourism demand;

- Gross fixed capital formation in tourism, as a proxy for the regional physical capital in tourism;

- Share of tourism in regional employment and in gross value added, as measures of the regional level of specialisation in tourism;

- Share of the workforce with tertiary education as a measure of the level of the qualifications of workers in the region;

- Share of the expenses in research and development in the regional GDP, as a measure of the regional efforts on innovation;

- Productivity in the tourism sector (gross value added/number of workers) as a measure of the regional ability to integrate knowledge into the production process and the efficient use of its resources;

- $W$ is a nonnegative $N \times N$ matrix of known contiguity parameters describing the spatial impacts among the regions considered in this study; the element $\mathrm{w}_{i j}$ indicates the intensity of the relationship between cross-sectional units $i$ and $j$; as no region can be its own neighbour, the diagonal elements are set to zero; neighbourhood is defined by "rook-contiguity" (when there is a common portion of the border between two regions); a score of 1 has been assigned for the case of immediate neighbours (contiguity level 1) and a score of 0.5 has been assigned for the "neighbours of neighbours" (contiguity level 2); the lines of this matrix have been normalized, assuming that the potential spinoff effects are the same for all regions, independently of the number of neighbours;

- WY represents the endogenous interaction effects among the dependent variables;

- Wu shows the interaction effects among the disturbance terms of the different units;

- $\rho$ is called the spatial autoregressive coefficient (identifying the spatial lag);

- $\lambda$ the spatial autocorrelation coefficient (identifying the spatial error); 
- $i$ is an index for the regions and $t$ is an index for the time period concerned.

The identification of the potential spatial effects, both related to the endogenous variable and/or the error term, requires the computation of a series of tests (Baltagi, Song, \& Koh, 2003; Baltagi, Song, Jung, \& Koh, 2007) that can be computed using the splm package in $R$ (Milo \& Piras, 2012). Depending on the results of these tests, a spatial lag model is applied when the error term is only identified for the dependent variable $(\lambda=0)$, or otherwise a spatial error model is used in case the spatial effects are exclusively identified for the distribution of the error terms $(\rho=0)$. If both $\lambda$ and $\rho$ are different from 0 , the general spatial model will be applied.

For the joint LM (Lagrange Multiplier) test for no random effects and no spatial autocorrelation ( $\mathrm{H} 0: \lambda=\rho=0$ ), a score of 4452.934 with a $p$-value $<2.2 \mathrm{e}^{-16}$ was obtained, leading to the rejection of the null hypothesis. This result suggests the existence of spatial effects linked to the dependent variable and/or to the error term, requiring other tests to be performed. Nevertheless, the results for the Moran-I test computed in the previous section suggested already the existence of spatial effects for the dependent variable $(\rho \neq 0)$.

The (non-)existence of spatial effects among the dependent variable (H0: $\rho=0)$, assuming the non-existence of spatial effects in the error term $(\lambda=0)$, is the second test to be performed (using the Baltagi, Song and Koh SLM1 test). In this case, the null hypothesis is accepted, since a score of 0.034 with $p$-value $=.973$ is obtained. This implies that, if there is no spatial effect within the error terms, there is no spatial effect either among the dependent variable. Conversely, the SLM2 marginal test examines the inexistence of spatial effects among the error term (H0: $\lambda=0)$; since the assumption of no spatial effect for the dependent variable $(\rho=0)$ led to a score of 0.0117 with $p$-value $=.9907$, this also leads to the rejection of the null hypothesis. Thus, if there is no spatial lag identified in the data, it is possible to conclude that no spatial error effect occurs either.

Finally, the Baltagi, Song and Koh conditional test LM $\lambda$ seeks to test the inexistence of spatial effects in the error term (H0: $\lambda=0)$, independently of the existence (or not) of spatial effects related to the dependent variable $(\rho=0$ or $\rho \neq 0)$. In this case, the null hypothesis is rejected, since a score of 34.294 with $p$-value $<2.2 \mathrm{e}^{-16}$ was obtained. Thus, it is possible to conclude for the existence of spatial effects among the error terms.

Considering the existence of both types of spatial effects, a general spatial Cliff-Ord type model (Cliff \& Ord, 1981) will now be computed, including a spatially lagged dependent variable and a spatially autocorrelated error term. Finally, the option between a random or fixed effects model has been supported by the result of a Spatial Hausmann test ( $p$-value $<2.2 \mathrm{e}^{-16}$ ), leading to the choice for a fixed effects model.

The previously presented expression (2) leads to a model with:

$$
Y=\log \mathrm{GVA} ; X=\log \mathrm{NIT}+\log \mathrm{INV}+\mathrm{EMPTS}+\mathrm{GVATS}+\mathrm{EDUC}+\mathrm{ID}+\text { Prod }
$$

This model includes fixed individual effects (related to time, which provided better estimates than those obtained with fixed effects for individuals) and specifies the spatial impacts related both to the endogenous variable and to the error term ("kkp" type) (Kapoor, Kelejian, \& Prucha, 2007). The estimation of the model was based on a maximum likelihood technique (also using the package splm for $R$ ). The results are presented in Table 2 (parameters for each variable) and Table 3 (fixed time effects).

The model confirms the expected positive correlation between tourism performance, tourism demand, investment in the tourism sector and the level of specialisation in 
Table 3. Estimates for the fixed (time) effects.

\begin{tabular}{lrcrc}
\hline Time & Estimate & Std. error & $t$-Value & $\operatorname{Pr}(>|t|)$ \\
\hline 2004 & -0.007 & 0.146 & -0.048 & 0.962 \\
2005 & 0.011 & 0.147 & 0.078 & 0.938 \\
2006 & 0.016 & 0.147 & 0.110 & 0.912 \\
2007 & 0.039 & 0.146 & 0.263 & 0.048 \\
2008 & 0.041 & 0.146 & 0.276 & 0.782 \\
2009 & -0.027 & 0.146 & -0.182 & 0.855 \\
2010 & -0.027 & 0.146 & -0.187 & 0.852 \\
2011 & -0.045 & 0.147 & -0.310 & 0.757 \\
\hline
\end{tabular}

tourism, when measured by the share of the gross value added by this sector within the overall regional gross value added. Nevertheless, when specialisation is measured taking into consideration the share of the work force employed in tourism, a negative correlation with tourism performance can be found. This suggests that regions where the tourism sector is more labour-intensive achieve lower levels of productivity and also relatively lower levels of gross value added in the tourism sector.

It was also possible to infer that productivity in the tourism sector, qualifications of the regional work force and regional investment in research and development have the expected positive impacts on the performance of the tourism sector. On the other hand, despite their low level of statistical significance, the time effects clear identify a negative impact on gross value added in the tourism sector after 2008 (with negative estimates for every year until 2011), reflecting the impact of the international financial crisis, which started in 2007, on tourism.

The existence of spatial effects among regions is also clear. These include positive spillover effects, expressed in the value of the spatial autoregressive coefficient (suggesting that tourism dynamics in one region has positive impacts on the contiguous regions) and also positive unmodelled effects, expressed in the value of the spatial autocorrelation coefficient).

\section{Discussion}

The results of our econometric model have confirmed the expected positive impacts on the tourism performance of tourism demand, investment and productivity in the tourism sector, qualifications of the regional work force and regional investment in research and development. Nevertheless, when the impacts of the level of specialisation in tourism are taken into account, we may identify a positive impact when this is measured by the share of the gross value added in tourism within the regional economy, but a negative impact when it is measured by the share of employment in tourism. This offers an explanation for the lower levels of productivity in the regions where tourism services are more labour intensive, suggesting that tourism supply in those regions is based on products and services with low value added.

Confirming that tourism dynamics has an heterogeneous spatial distribution, tending to concentrate around clusters of regions (as observed by Kang et al., 2014; Zhang et al., 2011; or Majewska, 2015), our exploratory spatial analysis also revealed the existence of a large number of Southern European regions (where the major mass tourism sun-and-sea destinations are located) with high levels of specialisation in tourism and relatively low achievements in terms of value added. This has important implications for those destinations, as it 
reveals the existence of a high pressure on local resources (normally ecologically sensitive), with a relatively low impact on the regional economy and, consequently, low benefits for the local population. Adequate policies oriented to increase the value added of these services (through the diversification of local supply, integrating other types of endogenous resources into the tourism services, developing a strategy of product diversification, as proposed by Benur \& Bramwell, 2015) may lead to the achievement of a higher economic performance, reducing the negative impacts on the environment and landscapes. This also seems to be in accordance with the results obtained by Milio (2014), observing that European regions highly specialized in tourism tend to reveal more difficulties to return to a growth path after suffering from a negative external shock, like the international crisis started in 2007.

These problems are also reflected in the spatial distribution of the clusters relating tourism performance to education, innovation and productivity. Despite the positive correlation between these factors and tourism performance identified in the econometric model, our exploratory analysis revealed the existence of a very limited number of clusters of regions where high levels of tourism performance are related to high scores achieved in any of those factors. On the other hand, a large number of clusters of regions show low values for the gross value added in tourism, despite the high scores found for productivity, education and $R \& D$. These results seem to confirm the conclusions obtained by Yang and Cai (2015) or Úbeda-García et al. (2014), observing that high qualifications of the labour force are mostly related to the performance of high quality establishments or to the implementation of competitive strategies based on differentiation (rather than cost leadership). In this sense, labour productivity can be seen, as proposed by Cvelbar et al. (2015), as a relevant indicator of tourism competitiveness.

This result clearly shows the importance of a balanced and diversified regional economic structure, where tourism has close links to other sectors and the integration of knowledge into innovation processes, as proposed by the recent conceptual developments related to the "smart tourism" approach (Boes et al., 2016) or to the policy guidelines related to the "smart specialization" concept (Foray et al., 2012; Piirainen et al., 2017). In fact, despite the importance of gross value added or investment in tourism for Southern European regions (identified in Figures 2, 3, 6 and 7) there is a clear lack of connection between tourism, education and productivity, which should be a major concern for tourism destination policies and service management in these territories. It is clear that regions where education, innovation and productivity assume more importance (Figures 4, 5 and 8 ) are also those where gross value added in tourism is less important for the regional economy.

The results of the spatial panel data model and the exploratory spatial analysis developed in our study clearly revealed that contemporary regional tourism activities are also linked to the dynamics observed in neighbouring regions and not only to the resources and conditions available in each region separately. In this case, the positive spatial effects (both the spillover effects related to tourism competitiveness and also the spatial unmodelled effects expressed in the error term) suggest that cooperation among clusters of destinations (even if located in different regions or countries) has potential mutual benefits, despite the market competition among them.

This has clear implications for tourism service management and destination policies, including broader regional policies, in order to increase the connections and interaction between tourism, other economic sectors, knowledge and innovation, as seems to be expressed also by the general purposes defined by the smart specialisation principles assumed for contemporary regional policies within the European Union. Moreover, cross-border initiatives (as suggested by Weidenfeld, 2013) can be particularly relevant 
for regions with lower levels of technological development and labour qualifications. This inter-regional cooperation can be oriented to both the "productivity spillovers" (labour movement and demonstration effects) and the "market access spillovers" (joint promotion, mostly for multi-destination travellers) proposed by Yang and Wong (2012).

Our results reveal a modest importance of research and development activities in regions where tourism specialization is high, suggesting a low contribution of the knowledge sector for the regional economy, despite the potential of tourism services to integrate knowledge and new technologies, mostly related to ICT or media production. This is also related to spatial inequalities observed by Hansen and Winther (2011) regarding the concentration of research-intensive economic activities in specific clusters of regions, which are different from those where tourism plays a more prominent socio-economic role. Nevertheless, the complex relations between regional innovation systems and the tourism sector observed by Rodríguez et al. (2014) suggest that more detailed future studies, including other type of information, can contribute for a better clarification of these problems.

The low value added generated by tourism activities in those Southern European regions also suggests weak linkages to other economic sectors of the region, which could contribute to enlarge and to diversify the value chain of tourism products and services, with higher socio-economic impacts on the territory. As the Smart Specialization strategies recently implemented in European regions address these two factors - the contribution of knowledge for the economy and the reinforcement of linkages between related economic sectors -, an improvement in the performance of these regions in terms of value added by tourism can be expected. This question can be addressed in the near future, when the results of the strategies under implementation may be observed.

\section{Conclusion}

The main contribution of this work relates to an original causal analysis, at the international level, of the impacts of regional innovation dynamics (a "macro-level" analysis of innovation in tourism, as defined by Medina-Muñoz, Medina-Muñoz, \& Zuñiga-Collazos, $2013 \mathrm{~b}$ ), production factors, productivity and specialization on regional tourism competitiveness. This analysis can be framed within the model proposed by Medina-Muñoz, Medina-Muñoz, and Chim-Miki (2013a), which suggests the adoption of both the definitional approach and the explanation approach (also stressed out by Mazanek et al., 2007) for the analysis of tourism competitiveness

Even though our work did not aim at analysing all the possible determinants of tourism competitiveness (as systematized, for example, by Ritchie \& Crouch, 2003; Mazanek et al., 2007; or Medina-Muñoz, Medina-Muñoz, and Chim-Miki (2013a), it was possible to obtain relevant results with practical policy and managerial implications, based on the causal analysis of the impacts of determinants of tourism competitiveness related to innovation dynamics and the above mentioned contextual regional characteristics.

Taking into consideration, the difficulties to obtain precise indicators to assess innovation processes within the tourism sector, as pointed out by Hjalager (2010) or MedinaMuñoz, Medina-Muñoz, and Zuñiga-Collazos (2013b), further developments of this work can be oriented to overcome this problem, by analysing the specific innovation dynamics of the tourism sector.

Moreover, this study also confirms the research potential of spatial econometric analysis - and in particular spatial autocorrelation techniques - for tourism studies. Only a few such studies have been undertaken in this field, but the existence of spatial patterns in tourism activities and its determinants can clearly be observed through this methodological 
approach. Therefore, our analysis contributed to shade some light on the spatial agglomeration processes related to tourism and innovation dynamics, revealing the heterogeneity of European regions, while stressing the importance of inter-regional cooperation at policy level.

The increasing volume of geo-referenced information available at different territorial scales will certainly open new opportunities in the near future. For example, a more detailed analysis of tourism destinations (using NUTS-3 data instead of NUTS-2 data) could be an interesting and fruitful endeavour, although, for the time being, it is not yet possible to obtain the necessary relevant and comparable data.

\section{Disclosure statement}

No potential conflict of interest was reported by the authors.

\section{Funding}

João Romão is pleased to acknowledge financial support from Fundação para a Ciência e a Tecnologia and FEDER/COMPETE (grants UID/ECO/04007/2013 and SFRH/BPD/98938/2013).

\section{ORCID}

João Romão (1D http://orcid.org/0000-0001-6024-2624

\section{References}

Anselin, L. (2005). Exploring spatial data with GeoDaTM: A workbook. Urbana: Center for Spatially Integrated Social Science.

Anselin, L. (2010). Thirty years of spatial econometrics. Papers in Regional Science, 89(1), 3-25.

Asheim, B., Smith, H. L., \& Oughton, C. (2011). Regional innovation systems: Theory, empirics and policy. Regional Studies, 45(7), 875-891.

Baltagi, B., Song, S., Jung, B., \& Koh, W. (2007). Testing for serial correlation, spatial autocorrelation and random effects using panel data. Journal of Econometrics, 140(1), 5-51.

Baltagi, B., Song, S., \& Koh, W. (2003). Testing panel data regression models with spatial error correlation. Journal of Econometrics, 117, 123-150.

Basile, R., Capello, R., \& Caragliu, A. (2012). Technological interdependence and regional growth in Europe: Proximity and synergy in knowledge spillovers. Papers in Regional Science, 91(4), $697-722$.

Benur, A. M., \& Bramwell, B. (2015). Tourism product development and product diversification in destinations. Tourism Management, 50, 213-224.

Boes, K., Buhalis, D., \& Inversini, A. (2016). Smart tourism destinations: Ecosystems for tourism destination competitiveness. International Journal of Tourism Cities, 2(2), 108-124.

Boschma, R. (2016). Smart specialisation and regional innovation policy. Welsh Economic Review, $24,17$.

Buhalis, D., \& Law, R. (2008). Progress in information technology and tourism management: 20 years on and 10 years after the internet - The state of eTourism research. Tourism Management, 29, 609-623.

Camisón, C., \& Forés, B. (2015). Is tourism firm competitiveness driven by different internal or external specific factors? New empirical evidence from Spain. Tourism Management, 48, 477-499.

Capello, R., Caragliu, A., \& Nijkamp, P. (2011). Territorial capital and regional growth: Increasing returns in knowledge use. Tijdschrift voor Economische en Sociale Geografie, 102(4), 385-405.

Cliff, A., \& Ord, J. (1981). Spatial processes, models and applications. London: Pion.

Cooke, P. (2001). Regional innovation systems, clusters, and the knowledge economy. Industrial and Corporate Change, 10(4), 945-974. 
Cvelbar, L. K., Dwyer, L., Koman, M., \& Mihalič, T. (2015). Drivers of destination competitiveness in tourism: A global investigation. Journal of Travel Research, 55(8), 1041-1050.

Dwyer, L., \& Chulwon, K. (2003). Destination competitiveness: Determinants and indicators. Current Issues in Tourism, 6(5), 369-414.

Elhorst, J. (2003). Specification and estimation of spatial panel data models. International Regional Science Review, 26, 244-268.

Elhorst, J. (2014). Spatial econometrics: From cross-sectional data to spatial panels. New York, NY: Springer.

Enright, M., \& Newton, J. (2004). Tourism destination competitiveness: A quantitative approach. Tourism Management, 25, 777-788.

European Commission. (2006). Innovation in tourism - How to create a tourism learning area. Brussels: Author.

European Commission. (2007). Agenda for a sustainable and competitive European tourism. Communication from the Commission - COM/2007/0621. Brussels.

Florax, R., \& Vlist, A. (2003). Spatial econometric data analysis: Moving beyond traditional models. International Regional Science Review, 26(3), 223-243.

Foray, D., Goddard, J., Beldarrain, X., Landabaso, M., McCann, P., Morgan, K., ... Ortega-Argilés, R. (2012). Guide to research and innovation strategies for smart specialisation. Brussels: S3P European Union, Regional Policy.

Hansen, T., \& Winther, L. (2011). Innovation, regional development and relations between high- and low-tech industries. European Urban and Regional Studies, 18(3), 321-339.

Hassan, S. (2000). Determinants of market competitiveness in an environmentally sustainable tourism industry. Journal of Travel Research, 38(3), 239-245.

Hjalager, A. (2010). A review of innovation research in tourism. Tourism Management, 31, 1-12.

Kang, S., Kim, J., \& Nicholls, S. (2014). National tourism policy and spatial patterns of domestic tourism in South Korea. Journal of Travel Research, 53(6), 791-804.

Kapoor, M., Kelejian, H. H., \& Prucha, I. R. (2007). Panel data models with spatially correlated error components. Journal of Econometrics, 140(1), 97-130.

Kozak, M. (1999). Destination competitiveness measurement: Analysis of effective factors and indicators. European Regional Science Association conference papers, Dublin.

Liburd, J., \& Christensen, I. (2013). Using web 2.0 in higher tourism education. Journal of Hospitality, Leisure, Sport \& Tourism Education, 12, 99-108.

Ma, T., Hong, T., \& Zhang, H. (2014). Tourism spatial spillover effects and urban economic growth. Journal of Business Research, 68(1), 74-80.

Majewska, J. (2015). Inter-regional agglomeration effects in tourism in Poland. Tourism Geographies, 17(3), 408-436.

Marrocu, E., \& Paci, R. (2013). Different tourists to different destinations: Evidence from spatial interaction models. Tourism Management, 39, 71-83.

Martin, R. (2014). Path dependence and the spatial economy. In M. Fischer \& P. Nijkamp (Eds.), Handbook of regional science (pp. 609-629). New York, NY: Springer.

Mata, T., \& Llano-Verduras, C. (2012). Spatial pattern and domestic tourism: An econometric analysis using inter-regional monetary flows by type of journey. Papers in Regional Science, 91(2), $437-470$.

Mazanek, J., Wober, K., \& Zins, A. (2007). Tourism destination competitiveness: From definition to explanation? Journal of Travel Research, 46, 86-95.

Medina-Muñoz, D., Medina-Muñoz, R., \& Chim-Miki, A. (2013a). Tourism competitiveness assessment: The current status of research in Spain and China. Tourism Economics, 19(2), 297-318.

Medina-Muñoz, D., Medina-Muñoz, R., \& Zuñiga-Collazos, A. (2013b). Tourism and innovation in China and Spain: A review of innovation research on tourism. Tourism Economics, 19(2), 319-337.

Milio, S. (2014). Impact of the economic crisis on social, economic and territorial cohesion of the European Union (Vol. 1). Brussels: Directorate-General for Internal Policies, Policy Department B (Structural and Cohesion Policies).

Milo, G., \& Piras, G. (2012). splm: Spatial Panel Data Models in R. Journal of Statistical Software, 47 (1), 1-38.

Navickas, V., \& Malakauskaite, A. (2009). The possibilities for the identification and evaluation of tourism sector competitiveness factors. Engineering Economics, 1(61), 37-44. 
Neuts, B., Romão, J., Nijkamp, P., \& van Leeuwen, E. (2013). Describing the relationships between tourist satisfaction and destination loyalty in a segmented and digitalized market. Tourism Economics, 19(5), 987-1004.

O'Brien, R. M. (2007). A caution regarding rules of thumb for variance inflation factors. Quality and Quantity, 41(5), 673-690.

Paci, R., \& Marrocu, E. (2014). Tourism and regional growth in Europe. Papers in Regional Science, 93(S1), S26-S50.

Patuelli, R., Mussoni, M., \& Candela, G. (2013). The effects of world heritage sites on domestic tourism: A spatial interaction model for Italy. Journal of Geographical Systems, 15, 369-402.

Piirainen, K. A., Tanner, A. N., \& Alkærsig, L. (2017). Regional foresight and dynamics of smart specialization: A typology of regional diversification patterns. Technological Forecasting \& Social Change, 115, 289-300.

Racherla, P., Hu, C., \& Hyun, M. Y. (2008). Exploring the role of innovative technologies in building a knowledge-based destination. Current Issues in Tourism, 11(5), 407-428.

Ritchie, J., \& Crouch, G. (2003). The competitive destination: A sustainable tourism perspective. Oxfordshire: CABI International.

Rodríguez, I., Williams, A. M., \& Hall, C.-M. (2014). Tourism innovation policy: Implementation and outcomes. Annals of Tourism Research, 49, 76-93.

Romão, J., \& Neuts, B. (2017). Territorial capital, smart tourism specialization and sustainable regional development: Experiences from Europe. Habitat International, https://doi.org/10. 1016/j.habitatint.2017.04.006

Romão, J., Rodrigues, P. M. M., \& Guerreiro, J. (2017). Territory and sustainable tourism development: A space-time analysis on European regions. Region, 4(3), 1-17. doi:10.18335/region. v4i3.142

Sigala, M. (2009). Web 2.0, social marketing strategies and distribution channels for city destinations. In M. Gascó-Hernandez \& T. Torres-Coronas (Eds.), Information communication technologies and city marketing (pp. 221-245). Hershey: IGI Global.

Sigala, M. (2012). Exploiting web 2.0 for new service development: Findings and implications from the Greek tourism industry. International Journal of Tourism Research, 14, 551-566.

Sigala, M., \& Marinidis, D. (2012). E-Democracy and Web 2.0: A framework enabling DMOS to engage stakeholders in collaborative destination management. Tourism Analysis, 17(2), 105-120.

Song, H., Dwyer, L., \& Cao, Z. (2012). Tourism economics research: A review and assessment. Annals of Tourism Research, 39(3), 1653-1682.

Tödtling, F., \& Kaufmann, A. (2001). The role of the region for innovation activities of SMEs. European Urban and Regional Studies, 8(3), 203-215.

Tsai, H., Song, H., \& Wong, K. (2009). Tourism and hotel competitiveness. Journal of Travel and Tourism Marketing, 26(5), 522-546.

Tussyadiah, I., \& Fesenmaier, D. (2009). Mediating tourist experiences. Annals of Tourism Research, $36(1), 24-40$.

Úbeda-García, M., Cortés, E. C., Marco-Lajara, B., \& Zaragoza-Sáez, P. (2014). Strategy, training and performance fit. International Journal of Hospitality Management, 42, 100-116.

Weidenfeld, A. (2013). Tourism and cross border regional innovation systems. Annals of Tourism Research, 42, 191-213.

World Economic Forum. (2015). The Travel \& Tourism Competitiveness Report 2015. Geneva.

Yang, Z., \& Cai, J. (2015). Do regional factors matter? Determinants of hotel industry performance in China. Tourism Management, 52, 242-253.

Yang, Y., \& Fik, T. (2014). Spatial effects in regional tourism growth. Annals of Tourism Research, 46, $144-162$.

Yang, Y., \& Wong, K. K. F. (2012). A spatial econometric approach to model spillover effects in tourism flows. Journal of Travel Research, 51(6), 768-778.

Zhang, Y., Xu, J., \& Zhuang, P. (2011). The spatial relationship of tourist distribution in Chinese cities. Tourism Geographies, 13(1), 75-90. 